\title{
Estimation of the Degree of Saturation of Shallow Soils from Satellite Observations to Model Soil Slips Occurred in Emilia Romagna Region of Northern Italy
}

\author{
Lorella Montrasio $^{1}$, Roberto Valentino ${ }^{\mathbf{1}^{*}}$, Chiara Quintavalla ${ }^{1}$ \\ ${ }^{1}$ Department of Civil, Environmental, Territory Engineering and Architecture, University of Parma, Parma, Italy \\ E-mail: roberto.valentino@unipr.it \\ Received June 23, 2010; revised July 12, 2010; accepted August 2, 2010
}

\begin{abstract}
For the development of alert systems for soil slip occurrence, it is important to evaluate the degree of saturation of shallow soils $\left(S_{r}\right)$ over wide areas. Taking into account the possibility to estimate spatial and temporal variation of soil moisture using remote sensing techniques, a possible correlation between $S_{r}$ and the daily output of a sequential data assimilation system called ACHAB (Assimilation Code for HeAt and moisture Balance) has been studied. ACHAB is based on integrated use of remotely sensed land surface temperature (LST) and common data on meteorological forcing such as air temperature, wind-speed and incident solar radiation. The aim of this study is to understand if it is possible to use ACHAB output (a daily value of evaporative fraction for the whole Italian territory) to define the parameter $S_{r}$ that could be introduced in a simplified model for the description of soil slip triggering mechanisms on territorial scale.
\end{abstract}

Keywords: Degree of Saturation, Soil Slip, Satellite Observations

\section{Introduction}

Among different types of landslides, those involving small sections of superficial soils, often called soil slips, are particularly dangerous because of rapid formation, the difficulty in prediction and high density in distribution on a susceptible territory. The economic and social impacts of this kind of events have recently lead to the development of a simplified and physically based stability model called SLIP (Shallow Landslides Instability Prediction), able to foresee the occurrence of soil slips [1-3]. The model has been applied on local scale to some rainfall-induced shallow landslides occurred in the Italian territory [2-4] and has been implemented in a platform for a real-time territory control [5-6]. The model defines the safety factor of potentially unstable slopes taking into account the geometric characteristics of the slope, the geotechnical properties and the shear strength parameters of involved soils. Moreover, this method enables a direct correlation between the safety factor and rainfall depths through a simplified water-flow model.

For the improvement of the SLIP model and the development of alert systems for soil slip occurrence, it results important to evaluate and introduce the degree of saturation $\left(S_{r}\right)$ of shallow soils as a variable for the defi- nition of the safety factor.

The variations in soil water content in the upper soil layers are traditionally analyzed through a water balance equation. This balance is the algebraic sum, over a significant period, of inflowing (positive) and outflowing (negative) water mass from the soil-atmosphere interface. The water balance can be estimated using experimental techniques or numerical modeling. The spatial and temporal scale of the problem to be analyzed usually suggests the most appropriate choice between the two approaches. It is generally accepted that areas of limited extension can be effectively monitored by experimental devices for a limited period of time. On the other hand, the estimation of the overall water balance over wide areas and with reference to long periods of time is usually tackled by numerical modeling of infiltration and evapo-transpiration processes [7]. The choice of the numerical model implies the definition of some soil properties (water retention curve and permeability function) and some boundary conditions resulting from climate characteristics use and cover typology of the soil and groundwater aquifer depth [8].

In the SLIP model, while the geometric features of the slope and the physical characteristics of the soil can be reasonably considered unchangeable for a certain slope, 
the degree of saturation of the soil has to be evaluated changing in consequence of weather conditions and rainfalls. The shear strength parameters of the soil are, in turn, strongly influenced by the degree of saturation. Currently in the SLIP model $S_{r}$ is considered varying with seasonal trend, according to rainfall conditions.

Given the possibility to determine spatial and temporal variation of soil moisture using remote sensing techniques, it was possible to correlate the degree of saturation of the soil to the daily output of a sequential data assimilation system called ACHAB (Assimilation Code for HeAt and moisture Balance). This system is based on the integrated use of remotely sensed land surface temperature (LST), from satellite acquisition on a spatial resolution of $3 \mathrm{~km}^{2}$, and common data on meteorological forcing such as air temperature, wind-speed and incident solar radiation [9-10]. The model has been tested in two different versions: DS (Dual-Source) and API (Antecedent Precipitation Index).

The output considered in this analysis is the evaporative fraction $(E F)$, which represents the ratio between the energy consumed for evapo-transpiration and the net available energy and is related to the wetting history and dry-down in shallow soils.

This study attempts to correlate an energy balance parameter, such as $E F$, to an indicator of soil moisture, such as the degree of saturation, through data comparison. The aim of the study reported in this paper is to understand if it is possible to use ACHAB output (a daily output produced for the whole Italian territory) to define the parameter $S_{r}$ that has to be introduced in the SLIP model to foresee triggering mechanisms of soil slips on a territorial scale.

\section{The ACHAB Model}

The ACHAB model is a sequential data assimilation system, for the estimation of hydrological components related to land surface. The assimilation scheme allows the simultaneous collection of determinant parameters of land surface water and energy balance (turbulent transfer coefficient for heat fluxes, evaporative fraction, indices of soil moisture) with a very limited requirement of ancillary data and empirical assumptions. In addition to the system-state observations (Land Surface Temperature LST), the assimilation system requires common data on meteorological forcing such as air temperature, windspeed and incident solar radiation [11].

Two different versions of the model have been developed and tested:

1) ACHAB-DS: different contributions of soil and vegetation to the radiometric temperature are explicitly taken into account through dual-source formulation based on satellite vegetation indices;

2) ACHAB-API: the API equation is introduced into the assimilation scheme in order to model the soil mois- ture dynamics in a simplified way.

For the dual-source version of the model, which separates energy balances at the surface and gives two different results, the output parameter of evaporative fraction is evaluated for bare soils $\left(E F_{s}\right)$ and vegetated areas $\left(E F_{v}\right)$. For the API version, which gives only one result, the evaporative fraction is estimated using the API as constrain.

Figures 1(a, b, c) shows an example of evaporative fraction map for the Italian territory, obtained by the different versions of ACHAB model.

\subsection{Surface Energy Balance and Evaporative Fraction}

The evaporative fraction (EF) is defined as the ratio between the latent heat flux and the difference between net radiation and ground flux or, equivalently, the ratio between the latent heat flux and the sum of sensible and latent heat fluxes [12-14]:

$$
E F=\frac{\lambda E T}{R_{n}-G}=\frac{\lambda E T}{\lambda E T+H}
$$

where $\lambda E T$ is the latent heat flux, $R_{n}$ is the net radiation, $G$ is the ground flux and $\mathrm{H}$ is the sensible heat flux. In particular, the latent heat flux $(\lambda E T)$ is the energy, per time and surface units, that is exchanged between the earth's surface and the atmosphere (ET is evapo-transpiration). The latent heat is the energy that bonds water molecules in liquid phase and is released during a change of state from liquid into vapor. The energy released during the passage from liquid to vapor state does not generate a temperature increase but represents the potential energy of water vapor molecules. In Equation 1, the sensible heat flux $(H)$ represents the energy which can be evaluated by measuring air temperature with a thermometer.

Since $E F$ can be calculated over large areas using satellite imagery, it is a suitable indicator for the description of soil moisture conditions on a regional scale, while the traditional methods of study of soil moisture storage in the unsaturated zone (experimental techniques and numerical modeling) may present many problems [15].

\section{Comparison between EF Values and Field Data of the Degree of Saturation}

In order to determine a possible correlation between the $E F$ obtained from the ACHAB model and the effective soil moisture, $E F$ and soil moisture data on a limited area where compared. The considered study area is in San Pietro Capofiume (Bologna), located in the Emilia Romagna Region.

EF data, related to this area, have been evaluated from national scale maps produced every day by the ACHAB 


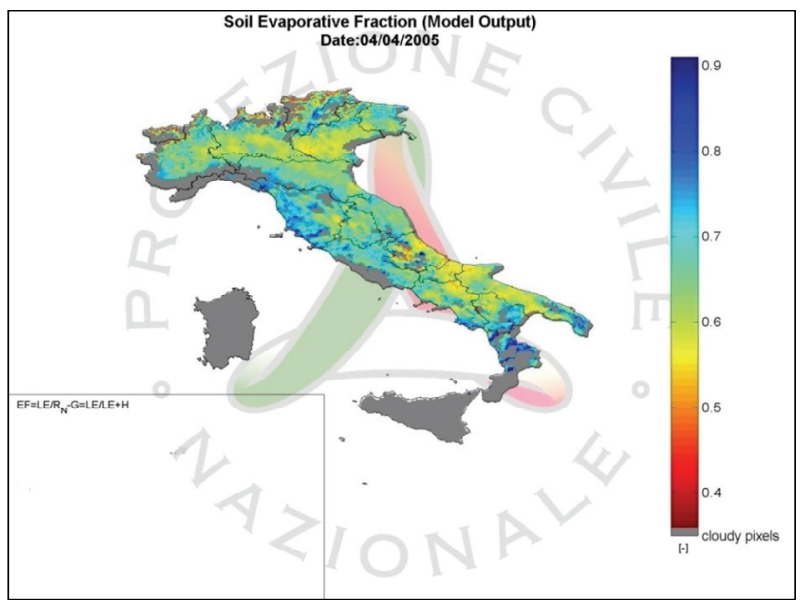

(a)

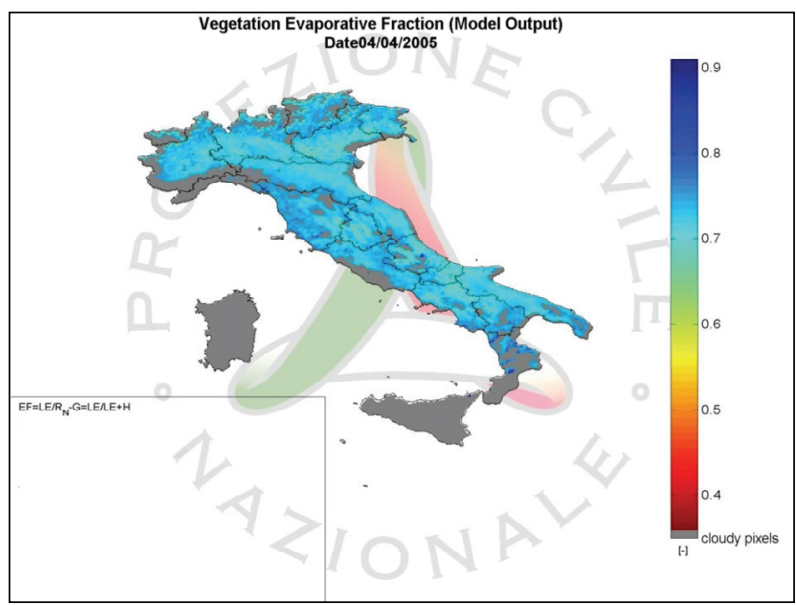

(b)

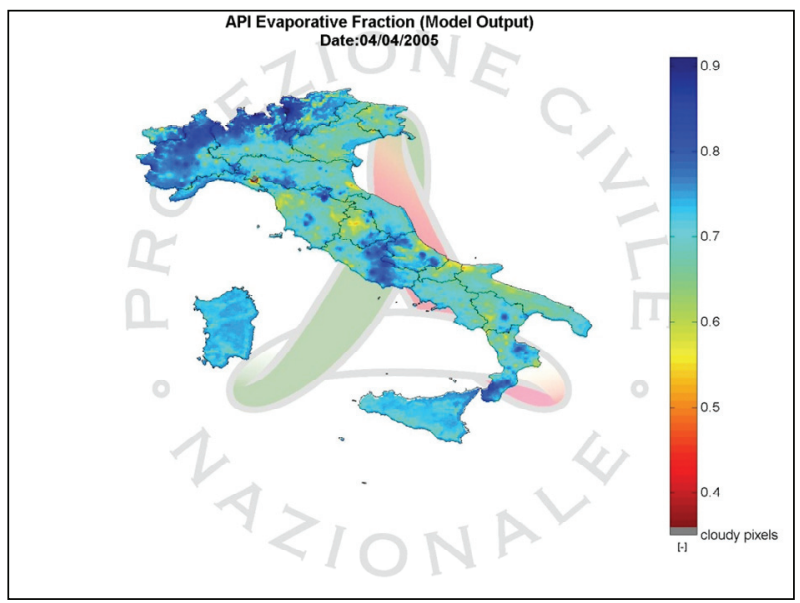

(c)

Figure 1. (a) Example of evaporative fraction map for Italian territory: output of ACHAB-DS bare soil; (b) Example of evaporative fraction map for Italian territory: output of ACHAB-DS vegetation; (c) Example of evaporative fraction map for Italian territory: output of ACHAB-API. model for the Italian territory. Using these data, an analysis of the temporal trend of the EF, for the period between March 2005 and January 2006, was carried out.

The analysis revealed that ACHAB-DS does not capture the seasonal variation in soil moisture, as the EF values remain on high even during summer (Figure 2). This behavior is especially highlighted in $E F$ data for vegetation (Figure 3). By analyzing the $E F$ data from the API version of the model a larger variability in the obtained values (probably related to rainfall intensities) is observed, but even in this case a seasonal trend cannot be seen (Figure 4).

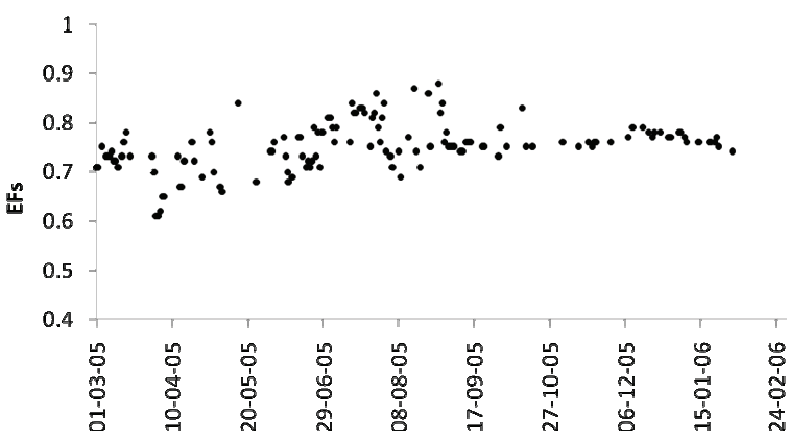

Figure 2. EF data for bare soil for San Pietro Capofiume site.

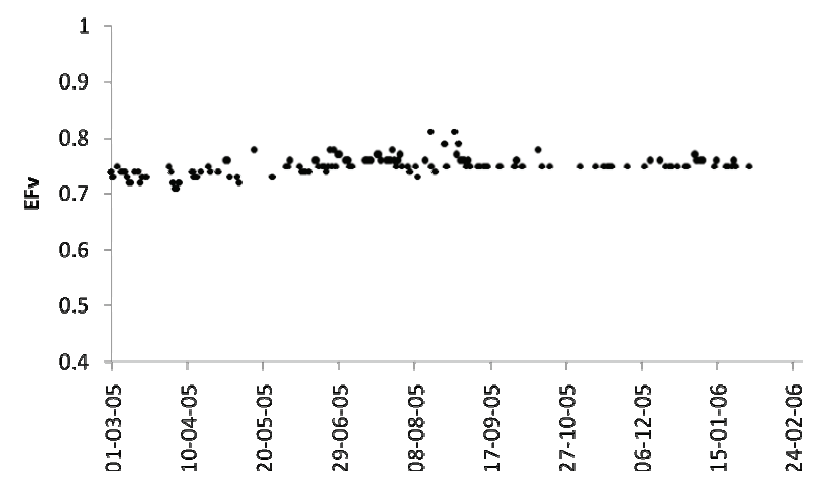

Figure 3. EF data for vegetated soil for San Pietro Capofiume site.

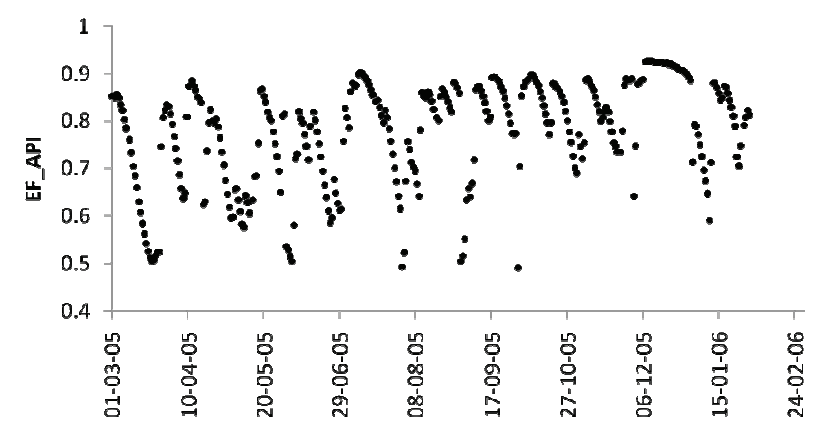

Figure 4. EF data from ACHAB_API for San Pietro Capofiume site. 
The soil moisture data used for the comparison, relative to the study area of San Pietro Capofiume, are obtained from field measurements of water content in the unsaturated zone carried out by the Regional Agency for Environmental Protection of Emilia Romagna Region. The soil moisture was monitored with Time Domain Reflectometry (TDR) devices, which were installed at seven different depths in the soil between 0.1 and $1.8 \mathrm{~m}$, corresponding to pedological profile layers [16]. The experimental measurements consisted of daily volumetric water content $(\theta)$ at each depth and refer to a period of almost three years, between September 2004 and April 2007. Over the same period, rainfall and temperature data are also available. The degree of saturation $S_{r}$ for each depth has been then calculated on the basis of the measured volumetric water content.

It is worth remember that the degree of saturation defines the water volume percentage $\left(V_{w}\right)$ in the volume of void space in the soil $\left(V_{v}\right)$ and can range from 0 , in completely dry soil, to 1 in saturated soil.

For the exact evaluation of soil saturation the parameter of effective saturation $\left(S_{e}\right)$ should be used. Effective saturation is usually calculated on the basis of volumetric water content by using the well known equation:

$$
S_{e}=\frac{\theta-\theta_{r}}{\theta_{s}-\theta_{r}}
$$

where $\theta$ is the volumetric water content, $\theta_{r}$ is the residual water content, which represents the adsorbed water, while $\theta_{s}$ is the saturation water content, which represents the maximum volumetric water content. In the present work, given the typology of the soils considered, which are prevalently sandy-silt with a percentage of clay no higher than that of $15 \%, \theta_{r}$ is assumed equal to zero. Considering the negligible effect of such approximation, the degree of saturation $\left(S_{r}\right)$ is considered equal to the effective saturation $\left(S_{e}\right)$ :

$$
S_{r}=S_{e}=\frac{\theta}{\theta_{s}}
$$

The degree of saturation $S_{r}$ is calculated through Equation 3 for each depth of the sample site.

An empirical relationship between evaporative fraction $E F$ and volumetric soil moisture content $\theta$ was investigated by some Authors on the basis of results of two large-scale field campaigns dedicated to soil moistureevaporation-biomass interactions, FIFE (First ISCLCP International Satellite Land Surface Climatology ProjectField Experiment) [17] and EFEDA (ECHIVAL Field Experiment in Desertification-Threatened Areas) [18-20]. In particular, as reported in [21], the following relationship which normalizes $\theta$ with saturated soil moisture content $\theta_{s}$ has been proposed:

$$
\frac{\theta}{\theta_{s}}=\exp \left(\frac{E F-a}{b}\right)
$$

where $a$ and $b$ are calibration parameters. The evaporative fraction is related to volumetric soil moisture through a standard regression curve that is independent of soil and vegetation type [21].

The normalization expressed through Equation (4) allows the empirical function to be applied to a wide range of soil types as it excludes soil specific limits such as saturated soil water content and dry bulk density. The accuracy of the relationship, which describes the moisture content of the entire root zone, has been validated with data collected from irrigated plains in Pakistan and Mexico [20-21].

Given a certain similarity between environmental conditions that characterize both the areas used for validation [21] and our sample sites, the empirical correlation expressed by Equation (4) has been used in the present work to obtain, from the EF data, the related values of degree of saturation, in order to compare them with the measured values of Sr. In particular, the parameter a has been set to 1, as reported in [21], for normalized soil moisture, while b assumes a value equal to 0.94 , according to a calibration procedure carried out with the available data.

In Figures 5-6 one can notice that the degree of saturation, which is estimated respectively from EFs and EF_API, has not the seasonal trend that characterizes experimental data.

The greatest differences between the estimated values of $S_{r}$ and measured values of $S_{r}$ occur in June and July, i.e., during summer. Furthermore, the estimated degree of saturation has shown a behavior that can be correlated only with the trend of the soil moisture in the shallow soil layer (at a depth of $0.25 \mathrm{~m}$ from the ground level), as one can observe from the comparisons in Figures 5-6. Comparisons between estimated and measured values of $S_{r}$ at greater depths in the soil have also been considered, but they are not reported here since there was not a good correlation between the data.

\section{Introduction of Output Data from ACHAB in the SLIP Model}

In order to evaluate whether the estimated values of the degree of saturation of the soil, derived from ACHAB system, could be used in the model for characterizing the triggering mechanism of shallow landslide [1,3], those data have been introduced in the SLIP model.

The SLIP model has been previously applied to 45 sites of the Italian Apennines in the Province of Reggio Emilia, where many rainfall - induced shallow landslides occurred in April 2005 [4]. In this model the degree of saturation currently takes into account the seasonal trend and assumes typical values that can range from 0.6, during the summer, to 0.9 in winter, within the limits of the superficial layers of the soil (depths in the range of 0.7 - 


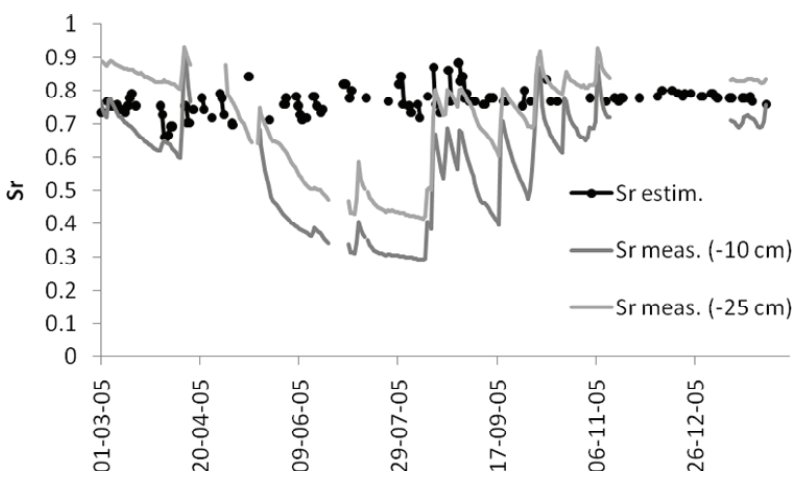

Figure 5. Comparison between estimated $S_{r}$ (from EFs data) and measured $S_{r}$ at depths of 10 and $25 \mathrm{~cm}$ for San Pietro Capofiume site.

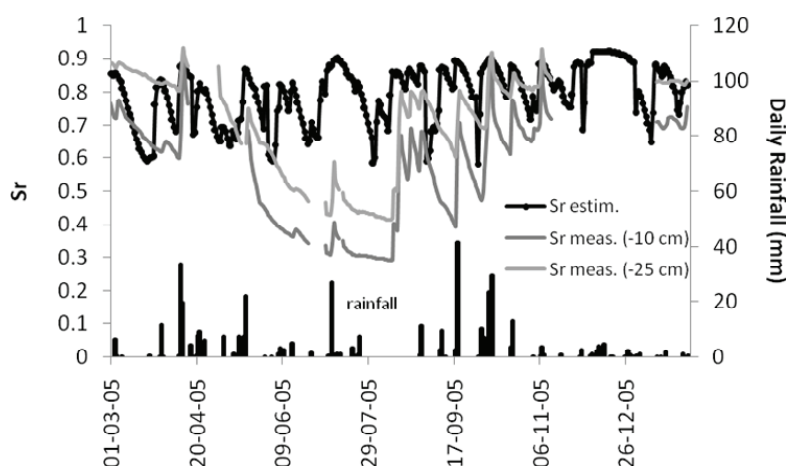

Figure 6. Comparison between estimated $S_{r}$ (from EF API data) and measured $S_{r}$ at depths of 10 and $25 \mathrm{~cm}$ for $S a n$ Pietro Capofiume site.

$1.0 \mathrm{~m}$ from the ground level) and especially in northern Italy regions. This trend is confirmed by many experimental observations [22], even by those realized in the San Pietro Capofiume site (Figure 7).

The SLIP model, with the simplified trend of the input parameter $S_{r}$, allows to obtain the behavior of the safety factor as a function of time and captures both the instability situation, i.e., $F_{s}=1$ in the expected date, and the stability conditions $\left(F_{s}>1\right)$ in the remainder of the time (Figure 8). It is worth notice that the instability condition can be reached when the degree of saturation is not so close to one, because the SLIP model is more sensitive to rainfall depths than to soil moisture degree. As an example, in Figure 8 is shown the result of the SLIP model applied to the site of Baiso (Emilia Romagna Apennine, Northern Italy), where a soil slips occurred on 10 April 2005.

The values of $S_{r}$ with seasonal trend in the SLIP model have been replaced by estimated values of $S_{r}$, obtained from the $E F$ data produced by ACHAB. The values of $S_{r}$ have been estimated for the examined time interval over two representative sites where the SLIP model has been applied: Baiso and Canossa. Through this modification, it is possible to observe that the trend of the safety factor for given test sites is significantly influenced by the change in values of the degree of saturation: in particular $F_{s}$ reaches values related to instability conditions $\left(F_{s}<1\right)$ even in periods that are not associated with real landslide phenomena. This seems to be due to the fact that the values obtained by ACHAB model do not capture a seasonal trend. Therefore, as it can be noticed by the graphs in Figure 9, in the Baiso site, after the introduction of $S_{r}$ values derived from bare soil evaporative fraction data (Figure 9(a)) and $S_{r}$ values derived from EF_API data (Figure 9(b)), the safety factor reaches values lower than one not only in April 2005, when the historical event of soil slip happened, but also in October 2005. A possible explanation of this fact is that, in the month of October, $S_{r}$ is indeed relatively high as a consequence of rainfalls and is not affected by the strong drying of the soil occurred during the summer, like it was previously supposed. Even analyzing the graphs for the study area of Canossa (Figures 10(a, b), it is clearly visible that the safety factor detects instability situations not only in April 2005, but even in November and December of the same year. In these months, the values of the estimated degree of saturation are higher than those hypothesized for the seasonal trend shown in Figure 7.

\section{Results and Discussion}

After the analyses carried out in the previous section, it is possible to state that the ACHAB model needs some improvements to make its outputs applicable to the SLIP model. The main problems detected by the comparisons (lack of seasonal trend in the EF values, differences between estimated and measured or modeled values of $S_{r}$ ) are probably related to the following facts:

- the ACHAB model, due to its estimation of energy balance at the surface, calculates values of EF correlated to the soil moisture of the shallow layer of the soil, up to near $0.25 \mathrm{~m}$ from ground level;

- EF is high during the summer, when the surface heating is at its peak. It happens because at this time seasonal precipitations moisten the surface and cooling shift toward the more efficient latent heat mechanism. So the sensible heat decreases while $E F$ value increases;

- the ACHAB model provides EF estimations with a spatial resolution of $3 \mathrm{~km}^{2}$, and with no correlation to the soil type, while the comparisons have been made with punctual field measurements and with modeled data dependent on soil porosity.

An important feature about the trend of the degree of saturation has emerged by analyzing the available data: the seasonal trend considered in the SLIP model catches properly the soil saturation because in the model the rainfalls (basic variable to evaluate soil moisture) are already taken into account as input parameters while the 


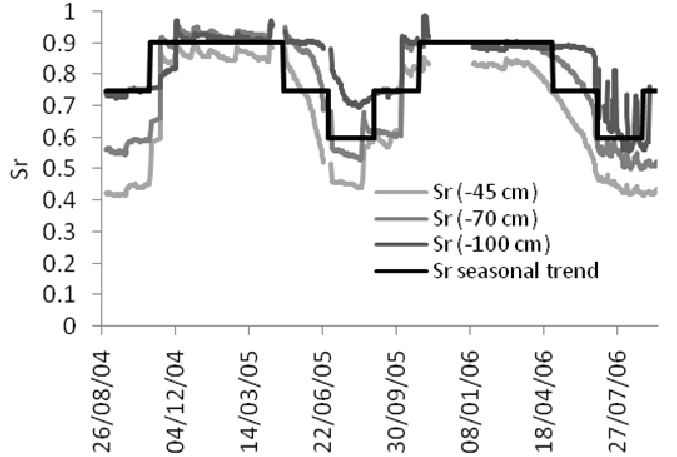

Figure 7. Comparison between experimental observations of $S_{r}$ at different soil depth in the San Pietro Capofiume site and $S_{r}$ considered changing with seasonal trend.

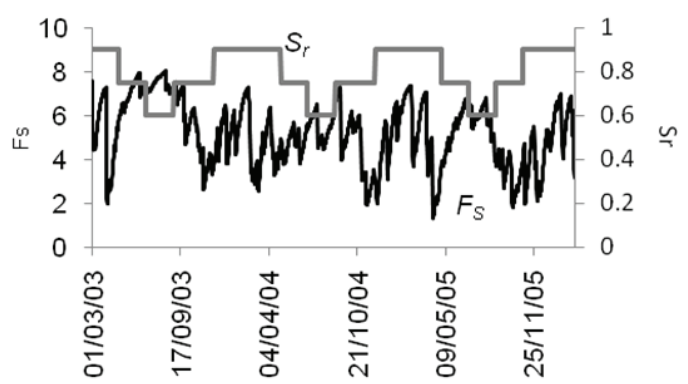

Figure 8. Behavior of the safety factor as a function of time in the site of Baiso, with the simplified trend of $S_{r}$.

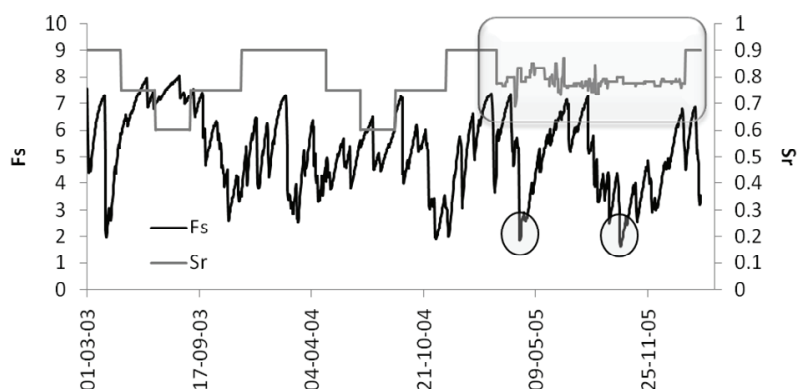

(a)

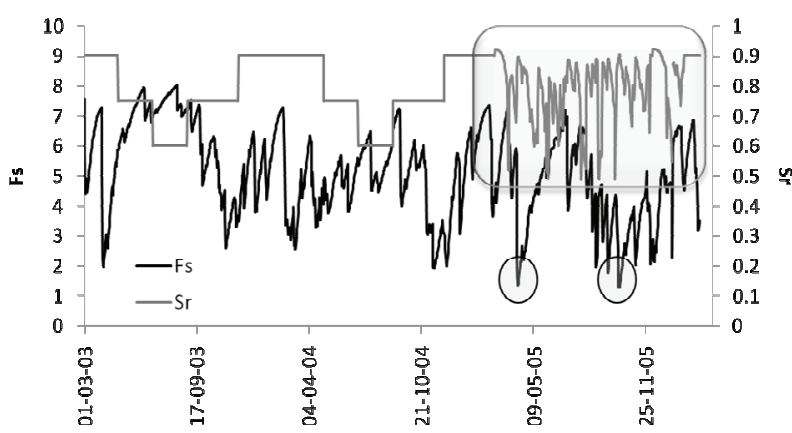

(b)

Figure 9. Trend of the safety factor as a function of time, in the site of Baiso. Is highlighted the introduction of $S_{r}$ values obtained from EFs data (a) and from EF_API data (b).

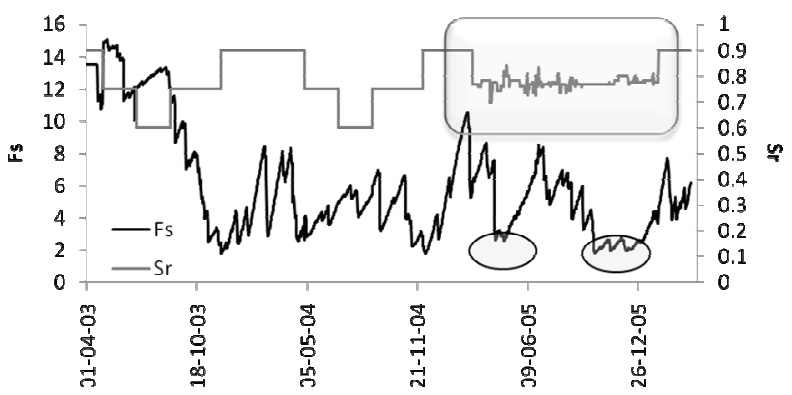

(a)

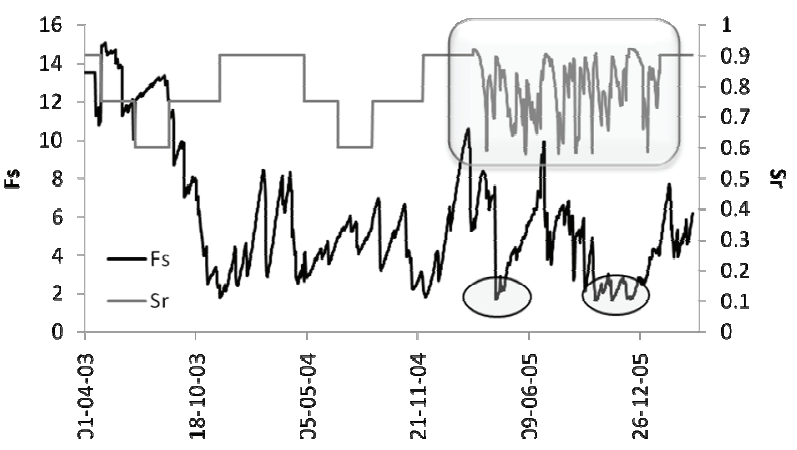

(b)

Figure 10. Trend of the safety factor as a function of time in the site of Canossa. Is highlighted the introduction of $S_{r}$ values obtained from $E F$ s data (a) and from EF_API data (b).

variable land surface temperature (that makes $S_{r}$ vary seasonally) is not considered as an input parameter of the model and is introduced by means of the trend of the degree of saturation.

In order to enable the use of $\mathrm{ACHAB}$ output for a more accurate estimation of the degree of saturation, which in its turn could be used in the SLIP model, the results of the present work suggest the following improvements for future works:

- the relationship between evaporative fraction and volumetric soil moisture content should be modified, on the basis of field measurements, in order to take into account the real moisture content at higher depths;

- calibration parameters of ACHAB model have to be modified dynamically (in time) in order to take into account seasonal weather conditions;

- ACHAB model could consider space-varying parameters to take into account different soil types.

\section{Conclusions}

Due to the need of rapid and reliable techniques for the estimation of the degree of saturation of soils, which are involved in rainfall-induced landslides, a new method of soil moisture detection using a remote sensing technique (the ACHAB system) has been analyzed, in order to 
evaluate the possibility of inserting the calculated values in the model for characterizing the triggering mechanism of shallow landslides (the SLIP model). To enable the use of $\mathrm{ACHAB}$ processing for a more accurate estimation of the degree of saturation, the ACHAB model should be improved through appropriate spatio-temporal parameters to provide estimation with a seasonal trend for different kinds of soil. Developing these changes, the ACHAB model results would be useful to determine the $S_{r}$ parameter and to take advantage of it in the SLIP model, especially in its implementation on a platform for a real-time territory control.

\section{Acknowledgements}

EF data were provided by the CIMA Foundation of Savona and Protezione Civile Nazionale, while experimental data of the degree of saturation were provided by ARPA-SIM Emilia Romagna (Regional Agency for Environmental Protection - Hydro-Meteorological Service). The authors would like to express their gratitude to Dr. R. Rudari, Dr. F. Tomei and Prof. M. Bittelli for their cooperation.

\section{References}

[1] L. Montrasio, "Stability Analysis of Soil Slip," Proceedings of International Conference Risk 2000, C. A. Brebbia, Ed., Wit Press, Southampton, 2000.

[2] L. Montrasio and R. Valentino, "Experimental Analysis and Modelling of Shallow Landslides," Landslides, Springer, Vol. 4, No. 3, 2007, pp. 291-296.

[3] L. Montrasio and R. Valentino, "A Model for Triggering Mechanisms of Shallow Landslide," Natural Hazards and Earth System Sciences, Vol. 8, No. 5, 2008, pp. 1149-1159.

[4] L. Montrasio, R. Valentino and G. L. Losi, "RainfallInduced Shallow Landslides: A Model for the Triggering Mechanism of Some Case Studies in Northern Italy," Landslides, Springer, Vol. 6, No. 3, 2009, pp. 241-251.

[5] L. Montrasio and R. Valentino, "X-SLIP: Un Modello per l'innesco di Frane Indotte da Piogge, Fisicamente Basato, Implementato su Piattaforma Experience," Proceedings of Annual Meeting of Italian Geotechnical Researchers, IARG 2009 (in Italian), Roma, September 2009.

[6] R. Valentino, L. Montrasio, and G. L. Losi, "Modellazione Dell'innesco di Frane Superficiali Indotte da Piogge: Dalla Scala Locale a Quella Regionale," Proceedings of Annual Meeting of Italian Geotechnical Researchers, IARG 2009 (in Italian), Roma, September 2009.

[7] M. Caruso, "Una Metodologia Teorica, Sperimentale e Numerica per la Previsione del Bilancio Idrico nei Terreni Superficiali non Saturi," Ph.D. Dissertation, University of Parma, Parma, 2007.
[8] B. R. Scanlon, R. W. Healy and P. G. Cook, "Choosing Appropriate Techniques for Quantifying Groundwater Recharge," Hydrogeology Journal, Vol. 10, 2002, pp. 18-39.

[9] G. Boni, F. Castelli and D. Entekabi, "Sampling Strategies and Assimilation of Ground Temperature for the Estimation of Surface Energy Balance Components," IEEE Transactions on Geoscience and Remote Sensing, Vol. 39, No. 1, 2001, pp. 165-172.

[10] F. Caparrini, F. Castelli and D. Entekabi "Variational Estimation of Soil and Vegetation Turbulent Transfer and Heat Flux Parameters from Sequences of Multisensory Imagery," Water Resources Research, Vol. 40, No. W12515, 2004, pp. 15-25.

[11] F. Caparrini, F. Castelli, D. Entekabi and L. Campo, "Sequential Assimilation of Land Temperature for Monitoring Surface Components of the Hydrologic Cycle," EUMETSAT Meteorological Satellite Conference, Helsinki, June 2006.

[12] C. H. B. Priestley and R. J. Taylor, "On the Assessment of Surface Heat Flux and Evaporation Using Large-Scale Parameters," Monthly Weather Review, Vol. 100, No. 2, 1972, pp. 81-92.

[13] J. L. Monteith, Principles of Environmental Physics, Edward Arnold Press, London, 1973.

[14] W. J. Shuttleworth, R. J. Gurney, A. Y. Hsu and J. P. Ormsby, "FIFE: The Variation in Energy Partition at Surface Flux Sites," In: A. Rango, Ed., Remote Sensing and Large-Scale Processes, Proceedings of the IAHS Third International Assembly, IAHS Publication, Baltimore, Vol. 186, 1989, pp. 67-74.

[15] F. Sini, "Satellite Data Assimilation for the Estimation of Surface Energy Fluxes," Ph.D. Dissertation, University of Basilicata, Potenza, 2005.

[16] A. Pistocchi, F. Bouraoui and M. Bittelli, "A Simplified Parameterization of the Monthly Topsoil Water Budget," Water Resources Research, Vol. 44, No. W12440, 2008.

[17] E. A. Smith, A. Y. Hsu, W. L. Crosson, R. T. Field, L. J. Fritschen, R. J. Gurney, E. T. Kanemasu, W. P. Kustas, D. Nie, W. J. Shuttleworth, J. B. Stewart, S. B. Verma, H. L. Weaver and M. L. Wesely, "Area-Averaged Surface Fluxes and their Time-Space Variability over the FIFE Experimental Domain," Journal of Geophysical Research, Vol. 97, No. D17, 1992, pp. 18599-18622.

[18] W. G. M. Bastiaanssen, H. Pelgrum, P. Droogers, H. A. R. de Bruin and M. Menenti, "Area-Average Estimates of Evaporation, Wetness Indicators and Topsoil Moisture during Two Golden Days in EFEDA," Agricultural and Forest Meteorology, Vol. 87, No. 2, 1997, pp. 119-137.

[19] W. G. M. Bastiaanssen, D. J. Molden and I. W. Makin, "Remote Sensing for Irrigated Agriculture: Examples from Research of Possible Applications," Agricultural Water Management, Vol. 46, No. 2, 2000, pp. 137-155.

[20] M. Ahmad and W. Bastiaanssen, "Retrieving Soil Moisture Storage in the Unsaturated Zone Using Satellite Imagery and Bi-Annual Phreatic Surface Fluctuations," Irrigation and Drainage Systems, Vol. 17, No. 3, 2003, pp. 141-161. 
[21] C. Scott, W. Bastiaanssen and M. Ahmad, "Mapping Root Zone Soil Moisture Using Remotely Sensed Optical Imagery," Journal of Irrigation and Drainage Engineering, ASCE, Vol. 129, No. 5, 2003, pp. 326-335.
[22] C. Quintavalla, "Valutazione del Grado di Saturazione in Terreni Superficiali per l'analisi di Stabilità di Pendii in Terra," MSc Thesis (in Italian), University of Parma, Faculty of Engineering, Parma, 2006. 